\title{
SOBRE PREDICATIVOS CONDICIONALES, PREDICADOS ESTATIVOS Y CUESTIONES CONEXAS'
}

\author{
M. a Antonia Martínez Linares \\ Universidad de Alicante \\ Antonia.Martinez@.ua.es
}

\begin{abstract}
Resumen
Firstly, this paper deals with the diversity and complexity of secondary predicates. Secondly, it deals with stage-level secondary predicates with conditional content. The paper focuses on two aspects of these elements: certain properties of the main predicates related to conditional interpretation of secondary predicates, and the place of these elements in the sentence structure.
\end{abstract}

\section{Sobre la diversidad de los complementos predicativos}

Si consideramos las caracterizaciones del 'predicativo"2 que ofrecen o asumen nuestros estudios gramaticales, resulta evidente que los rasgos que se le han asociado -entre ellos: atribuye una propiedad a un término formando parte de un predicado, puede concordar con ese término ${ }^{3} \mathrm{y}$, fundamentalmente, es un predicado secundario ${ }^{4}$ - pueden variar de modo independiente, de manera que unos constituyentes oracionales pueden presentarlos todos -Juan se acostó desnudo, Pedro caminaba pensativo- mientras que otros solo presentan alguno(s) y no siempre de modo claro. Así, por ejemplo, en Te creía en París, el locativo en Paris puede considerarse un predicado secundario que atribuye a la entidad indicada por te un estado pero, naturalmente, no puede concordar con su "sujeto semántico". En Nombraron presidente a Pedro, presidente, que especifica el cargo de Pedro resultante del nombramiento, sí concuerda con el objeto directo, pero es al menos discutible que consti-

\footnotetext{
1 Estc artículo forma parte de la investigación sobre "Verbos de estado en español. Modelos cognitivos y' procesos de estructuración categorial", financiada por el Ministerio de Ciencia y Tecnología. Ref. BFF2002-02442.

2 En el sentido del término en que denota un tipo de complemento diferenciado del 'atributo'. Otros términos equivalentes serían 'semiatributo', 'atributo no copulativo', 'atributo circunstancial'.

3 La centralidad de la categoría adjetivo como realización del predicativo explica que entre sus rasgos definidores se incluya a menudo la concordancia en género y número con el sujeto o con el objeto (véase, por ejemplo, Demonte y Masullo, 1999: 2463).

4 La condición de 'predicado secundario', vinculada al carácter léxicamente pleno del verbo núcleo del enunciado, se considera consustancial a la noción de 'predicativo'.

Se perfila, por tanto, como un constituyente que realiza una predicación sobre un término, en cuanto que le atribuye una propiedad o caracteristica, y es interpretable en términos de una estructura 'sujeto-predicado'; pero constituye una predicación secundaria, que carece de marcas flexivas y necesita integrarse en otra oración que legitime, que haga interpretable, csa relación predicativa.
} 
tuya un predicado secundario subordinado al verbo ${ }^{5}$, de ahí las discrepancias ${ }^{6}$, incluso entre estudiosos que parten de un mismo marco teórico, en el análisis de estos predicativos con 'verbos designativos'.

Por otro lado, es obvio que los constituyentes que se han venido catalogando como 'predicativos', tomando como base la condición -no siempre perspicua ${ }^{7}$ - de "predicados secundarios", no forman una clase homogénea de complementos; constituyen una clase amplia, una "gran bolsa", en la que se han ido incluyendo elementos que, si bien comparten alguna característica, si participan de un cierto "parecido de familia", pueden diferir en muchos aspectos -en la categoría, en el significado, en los vínculos con el verbo-, al tiempo que comparten propiedades con elementos frecuentemente categorizados mediante otros conceptos. De ahí que a veces pueda haber discrepancias sobre si un constituyente oracional -por ejemplo, los constituyentes destacados en Entró con sigilo, Vive con su madre - es un complemento predicativo -así catalogan" Demonte y Masullo (1999) con sigilo, con su madre- o queda mejor descrito como un complemento de otro tipo-modal, comitativo-; o que en los trabajos sobre los complementos predicativos haya sido un tema recurrente las relaciones entre los predicativos no seleccionados orientados al sujeto -los del tipo El niño dormía tranquilo- y los complementos de modo, fundamentalmente adverbios,

\begin{abstract}
5 Si se analiza como integrante de un 'núcleo verbal complejo' que configura una sola predicación, difícilmente podría entenderse como una 'predicación secundaria'.

6 El 'predicativo' en una construcción como Lo nombraron embajador se ha analizado en nuestros en nuestros cstudios gramaticales como integrante de "núcleo verbal complejo" nombrar embajador, que configura una sola predicación (Martínez Álvarez, 1986: 113; Fernández Leborans, 1999: 2364); como semejante a los clementos concordados, pero sin su "carácter predicativo" (Alcina y Blecua, 1975: 874); como representante de una predicación secundaria sin "contenido proposicional" y no seleccionada (al menos claramente) por el verbo (Demonte y Masullo, 1999: 2487); como integrante una 'oración reducida' o 'cláusula minima' seleccionada por el verbo (Suñer, 1990: 146), como Se considera guapo, pese a que "lamentablemente" no admite la paráfrasis por una completiva.
\end{abstract}

7 Dado que el predicativo es, por definición, un predicado secundario, son numerosos los lingüistas que han apuntado como prueba clara de la existencia de esa segunda predicación subordinada o incrustada la posibilidad de recuperarla mediante paráfrasis en las que las dos predicaciones - la correspondiente al predicativo y la nuclear-- queden desglosadas en sendas oraciones plenas coordinada o subordinadas. Se sucle advertir, no obstante -así lo hace, por ejemplo, Suñer (1990: 186)-, que el desglose de las dos predicaciones es sólo un método auxiliar que, "lamentablemente", no siempre se puede aplicar sin que ello signifique automáticamente que no existe un predicado secundario subordinado. Pero lo cierto es que cuando no es posible el desglose, como en el caso de Nombraron presidente a Pedro, se producen más discrepancias entre los análisis postulados, lo cual quizá indique una aplicación un tanto irrestricta del concepto de 'predicado secundario'.

Por ejemplo, Suñer (1990), e igualmente Demonte y Masullo (1999), analizan construcciones causativas del tipo El trabajo lo vuelve loco planteando que volver selecciona una 'cláusula mínima', 'reducida', de la que forma parte el predicativo, si bien Demonte y Masullo a continuación precisan que no "seleccionan en sentido estricto una cláusula mínima" (1999: 2507) y que "en ciertos casos el verbo" forma con el predicativo una unidad cuasiidiomática, un predicado complejo con un cuasi-auxiliar, lo cual, a mi juicio, supone afirmar que hay una sola predicación, que, de hecho, no hay un predicado secundario. Así pues, tal vez la posibilidad de paráfrasis por dos oraciones no sea condición sine qua non para ratificar la existencia de dos predicaciones. Pero también hay que admitir que cuando no existe esa posibilidad la predicación secundaria, consustancial al concepto de predicativo, se hace más difícil de justificar.

8 Asi catalogaba Gutiérrez Ordóñez (1986) el conjunto de las construcciones en las que podía darse una relación de atribución.

9 Según sus términos, se trata de sintagmas preposicionales que "alternan libremente con predicativos adjetivos y son a todos los efectos complementos predicativos" (1999: 2490). 
con los que tradicionalmente han estado, y siguen estando, vinculados ${ }^{10}$, o las semejanzas y diferencias con los 'adjetivos incidentales', cuya proximidad a estos predicativos hace que se mencionen frecuentemente como elementos con los que "no deben ser confundidos" (Porroche, 1990: 155; Fernández Leborans, 1995b: 365, Hernanz, 1993: 161, Demonte y Masullo, 1999: 2483).

Los complementos predicativos pueden diferir en su categoría, pues, aunque la categoría adjetivo es la más típicamente asociada a la función 'predicativo'", como predicativos se han analizado, no sólo adjetivos, participios y sustantivos -Me desperté entumecido, Te considero un mal bicho-, sino también sintagmas preposicionales de diversos tipos -Llegó angustiado y sin ganas de hablar, No te imagino en ese piso, Me miró en silencio (Marín Gálvez, 2000)- adverbios -El pescado huele bien (Demonte y Masullo, 1999)-, 'cláusulas absolutas' introducidas por la preposición con ${ }^{12}$-Llegó con la lengua fuera-, oraciones con verbo en forma personal -Salió que parecía un príncipe-, construcciones de gerundio -Ya nació bebiendo cerveza - o de infinitivo: Lo veo llegar todos los días.

Divergen asimismo en lo que concierne al lugar en que se ubican en la estructura oracional -distinto, por ejemplo, en De joven adoraba a su marido y Llegó con la lengua fuera ${ }^{13}$ o en sus vínculos con el verbo cuando forman parte del sintagma verbal: si en Pintó roja la valla el predicativo roja es un adjunto, en Te creía más listo el predicativo forma parte de la selección verbal. Y no se olvide, por otro lado, que también hay predicativos incluidos en un sintagma nominal: las fotos de María desnuda, la llegada de Ernesto borracho.

Es diferente su aportación semántica, vinculada a la construcción, pero también a la clase semántica del verbo y a la del complemento. Así, si consideramos los diversos tipos de predicativos que los estudios especializados han ido deslindando, es evidente que son distintos, por ejemplo, el significado de un predicativo orientado al objeto de carácter descriptivo -Se

10 Es, en efecto, sabido que la relación con los modales y, particularmente, con los adverbios de modo es un tema recurrente en el análisis de los predicativos. A la vinculación con el complemento circunstancial o con el adverbio apuntan caracterizaciones como "elemento de transición entre las funciones adjetiva y adverbial" (Gili Gaya, 1961: 79 n.223; RAE, 1973: 369), categoría "en la mitad del atributo y del adverbio" (Navas Ruiz, 1977: 29-30), reflejadas a su vez algunas de las denominaciones aplicadas a los predicativos: atributos circunstanciales, aditamentos atributivos, adverbios atributivos, adjetivos adverbiales o el cervantino "atribuadverbio" que sugería Navas Ruiz. Su proximidad al circunstancial o al adverbio se ha justificado por su condición de modificador del verbo, por la posibilidad de trocarse por adverbios -"dormian tranquilos es como si dijéramos dormian tranquilamente o con tranquilidad" (Navas Ruiz, 1977)-, o por una cierta "significación modal" que, por ejemplo, Gutiérrez Ordóñez (1986: 143) asigna a todos los atributos con verbos distintos de parecer, ser, estar, rasgos todos estos que, si bien suclen mencionarse a propósito del predicativo en general, afectan particularmente a los predicativos no seleccionados orientados al sujeto, cuyo comportamiento, por no "estar seleccionados", es, según Hernanz y Brucart (1987: 226), más adverbial que el de los que sí lo están.

11 Así lo reflejan, por ejemplo las denominaciones del tipo 'adjetivo adverbial', 'adjetivo atributivo' con que también se han distinguido, o el hecho de que la condición adjetiva se recoja, como la concordancia, en algunas definiciones de predicativo. En cualquier caso, el adjetivo suele señalarse en los estudios actuales como la categoría más común, la más "frecuente" (Demonte y Masullo: 1999), la "menos restringida", en cuanto que otros elementos necesitan ser "habilitados" o "transpuestos" para funcionar como predicativos.

12 Se trata de una construcción de carácter "perfectivo" y contenido "descriptivo" que puede funcionar como predicativo y responde a un tipo de construcción "muy productivo" (véase Suñer, 1999; Bosque, 1990; Hernanz y Suñer, 1999).

13 Con la lengua fuera, como predicativo no seleccionado orientado hacia el sujeto y de carácter descriptivo forma parte del sintagma verbal; de joven sería según Suñer (1990) un predicativo "dominado por tiempo" y tendría un carácter más periférico, de acuerdo con sus planteamientos. 
comió la carne cruda-, el del resultativo -Pintó la valla roja-, el de un predicativo seleccionado en 'cláusula mínima' en un enunciado estimativo - Te considero un buen tipo- y el de un predicativo dependiente de un verbo designativo: Lo nombraron presidente ${ }^{14}$. Aun cuando sean predicativos adjuntos orientados al sujeto, también difieren en su aportación semántica, por ejemplo, los predicativos introducidos por como que expresan una función social (Demonte y Masullo, 1999: 2468) - Me acompañó como Decano-y los predicativos descriptivos integrados por un adjetivo: Juan caminaba pensativo.

Hay diversidad semántica incluso en ese campo aparentemente más homogéneo y mejor acotado de los predicativos adjuntos orientados al sujeto de carácter descriptivo, que quizá son los ejemplares más típicos predicativos (fundamentalmente los constituidos por adjeti$\operatorname{vos})^{15}$. Así, los hay con una lectura "predicativa pura", diferenciada de la que puede aportar un 'adverbio de manera', como el de Juan caminaba pensativo, que equivale a "Juan estaba pensativo mientras caminaba"; pero también los hay con una lectura de "adverbio de manera" "orientada a la acción o el proceso" verbal (Demonte, 1999: 301), como los de Sus pasos resonaron monótonos (= monótonamente) o La tarde se extinguió lenta (=lentamente). Y quizá los valores de contenido de estos predicativos no se agoten con los dos mencionados. Así, no parece ajustarse a ninguna de estas dos lecturas el predicativo de Murió fusilado $^{16}$; ni el de Sonreía campechano, un adjetivo 'de propiedad' que denota 'disposición de ánimo', que no equivale a "Estaba campechano mientras sonréa" y parece admitir una interpretación adverbial (=campechanamente) pero 'orientada al sujeto', no al proceso verbal, y otro tanto ocurre con el adjetivo de "No lo creo", respondió enigmático. Tampoco se ajustan a la lectura 'adverbial' ni a la 'predicativa pura' los adjetivos de Murió pobre, El hombre nace naturalmente malo; puesto que las lecturas de pobre y malo son 'de propiedad' y no 'de estadio", equivalen a "Era pobre cuando murió", "El hombre es naturalmente malo cuando nace" y no a "Estaba pobre cuando murió", "El hombre está naturalmente malo cuando nace". De Miguel y Fernández Lagunilla (2002, 2003) sugieren que los adjetivos que admiten este tipo de paráfrasis con el verbo ser -no con estar- tienen estatus sintáctico de 'adjunto' más que de predicativo -en el sentido específico en que utilizan 'adjunto' como opuesto a predicativo ${ }^{17}$; ; pero lo cierto es que, según admite Fernández Lagunilla (1999) en el ámbito de los gerundios, resulta a veces difícil establecer diferencias formales que

14 En Pintó roja la valla el predicativo designa el estado del objeto resultante de la acción, en Se comió la carne cruda denota el estado inicial del objeto; en Te considero un buen tipo, el predicativo adsctibe al objeto una cualidad estable presentándola -a diferencia de Eres un buen tipo-como una opinión del hablante; en Lo nombraron embajador expresaría, según Demonte y Masullo, el título, implicado de manera específica el significado del verbo.

15 Constituyen el núcleo constante de los estudios gramaticales en el tratamiento de los complementos predicativos, en cuanto que se perfilan como elementos atributivos con verbos no copulativos en cualquiera de las extensiones del término 'verbo copulativo' y se ajustan, de forma no problemática, a la condición de predicado secundario, considerada consustancial al concepto de predicativo.

16 Según De Miguel y Fernández Lagunilla (2000: 35) fusilado denota, en este caso, "la manera en que se produjo el evento principal", pero "manera" resulta aquí un concepto muy laxo, no coincidente con el que tiene cuando se habla de 'adverbio de manera'.

17 Entiendo que utilizan 'adjunto' y 'predicativo' con un sentido similar al que asocia a estos términos Fernández Lagunilla (1999) en el tratamiento de las construcciones de gerundio. Distingue, entre los modificadores del verbo que "expresan una acción secundaria que se une a la acción denotada por el verbo principal constituyendo un solo evento" (1999: 3448-3449), los "gerundios predicativos y los gerundios adjuntos" (más adelante, adjuntos internos, para diferenciarlos de los adjuntos externos, que modifican a toda la oración): los primeros modifican al verbo y al SN sujeto u objeto; los segundos solo al verbo. 
identifiquen con claridad 'adjuntos' y 'predicativos' cuando la distinción se fundamenta ante todo en el contenido. Formalmente Murió pobre y El hombre nace naturalmente malo son semejantes a Mi abuela murió despierta y El niño nació sano, donde despierta y sano son predicativos claros; por tanto, si cabría considerar a pobre y naturalmente malo adjuntos por el contenido, también cabría considerarlos 'predicativos' por su estatus sintáctico, aunque con un contenido distinto del asociado al predicativo descriptivo.

Dada la diversidad semántica y estructural de los predicados secundarios orientados al sujeto o al objeto directo, es lógico que difieran también en sus condicionamientos. Es evidente, pongamos por caso, que no todos los predicativos han de ser 'episódicos' o 'de estadio', como se ha venido postulando para los predicativos no seleccionados. Los seleccionados 'en cláusulas mínimas', según destacan Demonte y Masullo (1999: 2503), pueden indicar "un estado contingente" - Te veo pensativo- o una "cualidad inherente" -como en $T e$ considero un buen tipo-, dependiendo, en parte, del verbo que selecciona al predicativo ${ }^{18}$. Pero incluso en el dominio de los predicativos no seleccionados orientados al sujeto resulta difícil formular generalizaciones que den cuenta, sin resquicios, de su distribución y de sus valores de contenido.

No cabe duda, a este respecto, de que las investigaciones en torno a los vínculos de índole léxico-aspectual entre los dos predicados -pieza clave de las investigaciones sobre este campo- abrieron una vía muy productiva para abordar los condicionamientos semánticos de estos predicados secundarios. Sirvieron, por ejemplo, para establecer el postulado de la incompatibilidad de los predicativos adjuntos del sujeto con los predicados de 'estado'; postulado que venía a matizar el supuesto previo de la ausencia de restricciones para estos complementos en función de las características de los verbos ${ }^{19}$, y servía de argumento para explicar la anomalía de algunos enunciados construidos con predicados principales de 'estado', como *María mide 2 metros contenta o *Juan pesa poco disgustado.

Sin embargo, conforme se ha ido profundizando en esa línea de investigación, se ha ido revelando que, para explicar la distribución y los valores significativos de estos predicados secundarios, no son suficientes las generalizaciones basadas en las grandes clases léxicoaspectuales de predicados.

Los conceptos de 'evento' y 'estado' no explican, por ejemplo, por qué Los encargados del zoológico adiestraban rígidos a sus animales ${ }^{20}$ es un enunciado al menos extraño, o por qué resulta aceptable Estaba sentado muy erguido en su silla, con un predicado de 'estado', en sentido amplio, ni dan cuenta de las diferencias de aceptabilidad entre Murió fusilado y *Se murió fusilado (De Miguel y Fernández Lagunilla, 2000) cuando el predicado principal es 'eventivo' en ambos casos.

Tampoco la eventividad unida al carácter 'inacusativo' y 'terminativo' - dos de los muchos rasgos léxico-aspectuales que se han asociado a la posibilidad de lectura 'adver-

18 Con los verbos volitivos, por ejemplo, "el predicativo solo puede ser perfectivo o de estado y no de cualidad inherente" (Demonte y Masullo, 1999: 2505)

19 Aún a finales de los 80 o principios de los 90 parecía aceptarse que no existian restricciones para este tipo de complemento en función de las características del verbo (Porroche, 1990: 168) o, "de sus propiedades aspectuales" (Demonte, 1991).

20 Este enunciado figura en el Anexo de Tornel, 1996. 


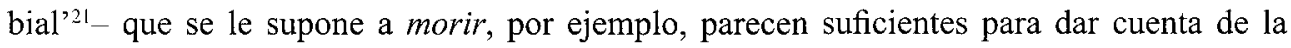
aceptabilidad del predicativo y su lectura adverbial en La tarde murió lenta, ya que ni es posible tal lectura en Mi abuela murió despierta ni resulta muy aceptable Mi abuela murió lenta, tal vez porque la tarde, pero no mi abuela, designa un evento que transcurre y lenta es un adjetivo 'de velocidad', pero no lo es despierta.

De ahí que en los últimos años ${ }^{22}$ se haya planteado la necesidad de tener en cuenta algo más que las clases léxico-aspectuales de predicados para explicar la distribución y las lecturas de los predicativos del sujeto no seleccionados: la estructura subeventiva, aspectos más concretos del significado de los dos predicados -como la estructura de qualia-, así como de otros componentes de los enunciados.

Cabe deducir, por tanto, que el análisis de los valores de contenido y los condicionamientos de los complementos predicativos, incluso limitado a la clase más típica de predicativos, puede resultar bastante complejo. $Y$ a esa complejidad contribuye, sin duda, la naturaleza a veces elusiva de las clases léxico-aspectuales con que operamos, pues, si bien son elementos clave en las generalizaciones, los limites entre clases resultan difusos, en parte, por la naturaleza de los predicados, en parte por la imprecisión del metalenguaje utilizado -'fase', 'cambio', 'dinamismo' 'homogeneidad', 'estado'- que hace difícil establecer si, pongamos por caso, esperar, ver, creer en algo, son 'procesos' o 'estados', y da pie a discrepar, por tanto, sobre si un predicado -Antonia se emocionó, por ejemplo- es 'estativo' -la falta de eventividad daría cuenta, a juicio de Demonte y Masullo (1999) de la anomalía de *Antonia se emocionó delicada - o es 'eventivo' por implicar 'cambio'.

Dado, además, que el estado descrito por el predicativo se destaca como relevante y específicamente relacionado con el proceso configurado por el predicado primario (Rapoport, 1993: 164, Halliday, 1967: 62) "bajo determinadas circunstancias comunicativas" (Penadés, 1991: 463), no ha de considerarse ajeno a la complejidad del análisis de los predicativos el hecho de que parece difícil saber, en muchos casos, si las anomalías de los enunciados que proporciona la introspección del lingüista para formular sus postulados se deben a razones de tipo gramatical o de carácter pragmático; si se deben a incompatibilidades entre clases de predicados o, simplemente, a que resulta difícil entender el estado descrito por el predicado secundario como relevante para el proceso significado por el predicado principal, como puede ser, por ejemplo, el caso de Adiestraban rígidos a los animales.

He recordado la extensión del concepto de 'predicativo', prácticamente acotado por la condición de predicado secundario del sujeto o del objeto directo de otro predicado; la diversidad sintáctica y categorial que lo relaciona y lo imbrica con otras categorías sintácticas; la variedad de los valores de contenido y la complejidad del tratamiento semántico que

21 Demonte (1999), Demonte y Masullo (1999) han vinculado la posibilidad de lectura adverbial "orientada hacia el proceso o acción" (Demonte, 1999: 301) a muy variados -y difíciles de sistematizar-aspectos de la semántica de los verbos: a su carácter inacusativo o inergativo, a la existencia en la estructura léxica de un componente "manera" o de componentes que expresan duración, a la referencia a un proceso de cambio de lugar o de cstado, a la denotación de "movimiento" "sin cambio de posición", al carácter incoativo o terminativo, a la implicación de límite, de "trayectoria" o "de lugar puntual". Si el verbo tiene significado "terminativo", si "designa una acción que se realiza en tanto que llega a un límite", como, a su juicio, ocurre llegar; entrar, morir, dormir "entre otros", "es posible entonecs la lectura de manera" (Demonte y Masullo, 1999: 2481). De ahi, desde su punto de vista, la lectura adverbial de La tarde se extingzió lenta.

22 Demonte, 1999; Demonte y Masullo, 1999; De Miguel y Fernández Lagunilla, 2000, 2002, 2003; Fernández Lagunilla y De Miguel, 2001. 
entraña incluso un solo tipo de predicativo -el que incluye los ejemplares más típicos--, así como el problema de los límites entre las anomalías debidas a razones gramaticales y las que pueden obedecer, simplemente, a que no existe un vínculo lógico entre los predicados relevante desde el punto de vista informativo, porque estimo que todo ello indica que no ha de considerarse totalmente acotado el dominio del 'predicativo' y sus tipos sintácticosemánticos ni, desde luego, podría tenerse por definitivamente zanjada la explicación de los valores de contenido y los condicionamientos semánticos.

Tal vez constituyan una ilustración de lo apuntado los enunciados del tipo María mide 2 metros descalza, que no parece encuadrable en ninguno de los tipos de predicativo que hasta ahora he mencionado y que resulta paralelo en su estructura a otros como * María mide 2 metros contenta, cuya anomalía se ha cifrado en la incompatibilidad léxico-aspectual entre los dos predicados.

Las notas que siguen versan sobre este tipo de enunciados que incluyen predicados secundarios de sentido 'condicional', un valor 'atributivo'23 que Halliday (1967) diferenciaba del 'descriptivo' y del 'resultativo', pero que, por lo que a mí se me alcanza, ha sido menos tratado como valor de los adjetivos u otros elementos 'atributivos' que se integran en el predicado "sin pausas" y atribuyen un estado al sujeto. Tratan sobre aspectos de los enunciados que parecen vincularse a ese contenido condicional, sobre la ubicación del predicativo en la estructura oracional y sus diferencias con respecto a los rasgos asociados a los predicativos adjuntos del sujeto pero también con respecto a otras categorías de predicaciones 'defectivas' (esto es, sin marcas verbales y dependientes de un predicado 'pleno'). Incluyen únicamente datos que precisan ser explicados pero creo que, al menos, sugieren, en la línea de lo anteriormente comentado, que hay predicados secundarios que, si no encajan en las características de los predicativos adjuntos del sujeto, tampoco se ajustan a las de otros tipos de predicaciones defectivas de modo claro y, de paso, que hay que ser precavidos a la hora de achacar a razones de índole léxico-aspectual las anomalías de los enunciados.

\section{Sobre los predicativos 'condicionales'}

\subsection{Predicativos adjuntos y predicados 'de estado'}

Como apuntaba anteriormente, enunciados integrados por predicados 'de peso y medida', como * Maria mide dos metros contenta (Suñer, 1999: 561), *Juan pesa poco disgustado (Demonte y Masullo, 1999: 2475) -al igual que otros constituidos por predicados 'clasificadores' (*María es escritora contenta), 'afectivos' (*María adora la música de Mozart entusiasmada), de 'percepción intelectual' (*Juan sabía francés contento)- han sido utilizados para ilustrar uno de los supuestos comúnmente admitidos en los estudios recientes sobre los complementos predicativos: la incompatibilidad de los predicativos adjuntos orientados al sujeto con las predicaciones principales de carácter estativo; incompatiblidad que se ha justificado por razones tales como que el predicado primario "ya indica

23 Halliday diferenciaba "attributive" (he drinks his coffee black) y "condition" o "conditional" (I can carry it empty), pero también decía que "condition" may be thought of as an abbreviation for "conditional-attributive" (1967: 78). 
que el sujeto se halla en un estado" (de Miguel y Fernández Lagunilla, 2002: 222) ${ }^{24}$ o que los predicados de estado carecen de "argumento eventivo" (Hernanz, 1988: 23) ${ }^{25}$, lo cual es una manera técnica de decir que no tienen "un valor de verdad restringido a fluctuaciones temporales" (Hernanz, 1988: 23), o que son insensibles al "Tiempo", de conformidad con Fernández Leborans (1995b: 379).

En efecto, los predicados 'de peso y medida' con los que se atribuye al sujeto una propiedad o característica (Demonte y Masullo, 1999: 2516; Cano Aguilar, 1981: 322), no solo son considerados comúnmente como 'estados' -concepto que puede resultar demasiado amplio, dado que se reconocen distintas clases de 'estados'-, sino que, de modo más específico, suelen clasificarse como predicados 'de propiedad' o 'de individuo ${ }^{26}$; esto es, predicados que asignan al sujeto propiedades que "no se realizan en ocasiones" sino que se configuran lingüísticamente ${ }^{27}$ como estables, como concebidas al margen de ubicaciones espaciales o temporales; de ahí que se destaque como propio de este tipo de predicados -entre otros rasgos ${ }^{28}$ - el rechazo de las localizaciones temporales concretas o su exclusión de cláusulas introducidas por cuando con un valor "temporal en sentido estricto"29 (Fernández Leborans, 1999: 2438; García Fernández, 1999: 3176). Pueden considerarse, por tanto, estados prototípicos, predicados "propia" o "auténticamente" estativos (Fernández Leborans, 1995: 267, Marín Gálvez, 2000), los únicos ${ }^{30}$ que, según Fernández Leborans (1995: 266), carecen realimente de una posición $<\mathrm{e}>$ para un argumento eventivo.

Es evidente, asimismo, que si bien disgustado, un participio, y contenta, un adjetivo 'de estadio', están capacitados para ser predicativos típicos ${ }^{31}$ y ocupan una posición característica de estos en *Maria mide dos metros contenta y *Juan pesa poco disgustado, no parecen tener la misma lectura que en María caminaba contenta (= Maria estaba contenta mientras caminaba) y en Juan se marchó disgustado (=Juan estaba disgustado cuando se marchó) donde son predicados adjuntos del sujeto, 'dominados por Aspecto', según ciertos

24 A ello añaden que, por tanto, "no parece posible que un segundo predicado ofrezca una información adicional o alternativa sobre lo que constituye la predicación fundamental del verbo sobre su sujeto" (2002: 222).

25 Como advierte Gutiérrez Ordóñez (1997: 29̀1-292) el "argumento eventivo", "que ha tenido una importancia capital en las reflexiones generativistas de la última década", no es un "argumento propiamente dicho: "una posición estructural que pueda ser ocupada por un sintagma", sino "un rasgo de significación".

26 Véase, por ejemplo, Laca (1999).

27 Otra cosa es, como señala Fernández Leborans (1995), que la propiedad sea objetivamente variable, que pueda cambiar en la "sustancia semántica" de la que se predica.

28 Como el hecho de que en presente no reciban una interpretación habitual o iterativa en cuanto que esta interpretación implica "pluralidad de actos" y realizaciones distintas con los mismos participantes (Laca, 1999: 904), propiedad que por otro lado está evidentemente ligada a las restricciones que presentan estos predicados para la combinación con complementos de frecuencia, con ubicaciones temporales (Pilkanen, 2002: 426): ${ }^{*} E s$ escritora frecuentementel el sábado por la mañana, con locuciones adverbiales del tipo cada día o todos los dias, que "remarcan la lectura habitual" (Marín Gálvez, 2000: 38) o para aparecer en una subordinada introducida por siempre que, cada vez que que también implica la posibilidad de que el hecho en cuestión tenga realizaciones espacio-temporales distintas *Siempre que Juan sabe francés les escritor, * Cada vez que pesa poco

29 Como *Cuando María mide dos metros o *Maria midió dos metros el sábado por la mañana. Según Fernández García, "las oraciones temporales tienen que contener un predicado que pueda sufrir cambios" (1999: 3176). Por ello los predicados 'permanentes' están excluidos de las relaciones temporales.

30 Los estados 'transitorios', 'episódicos', 'de estadio', que "tienen lugar en ocasiones" y son localizables en el tiempo y en el espacio, si tendrían, a su juicio, esa posición $<\mathrm{e}>$ para un argumento eventivo.

31 Como se indicó antes, otra de las generalizaciones que se manejan en el análisis de los predicativos típicos es que el predicado secundario ha de ser 'transitorio', 'de estadio', no 'de individuo'. 
planteamientos (véase Suñer, 1990), y dependientes de un predicado principal 'eventivo'. No admiten, en efecto, una paráfrasis "propiamente predicativa": \#Maria está contenta mientras mide dos metros, \#Juan está disgustado mientras pesa poco; pero lo cierto es que tampoco admiten, por ejemplo, las paráfrasis de los 'adjuntos' -en el sentido en que utilizan De Miguel y Fernández Lagunilla el término- o la de los predicativos 'dominados por Tiempo': \#María está contenta cuando mide dos metros, \#Juan está disgustado cuando pesa poco. Simplemente, no hay una lectura lógica que asignar a estos elementos. Sería, sin embargo, inadecuado deducir de ello que ha de ser anómalo todo enunciado que contenga un predicado principal estativo y un predicado secundario adjunto referido al sujeto, aun cuando no admita la lectura de los predicativos 'dominados por Aspecto'.

Maria mide dos metros descalza, Juan pesa poco/ 48 kilos desnudo/con los bolsillos vacíos $^{32}$, están construidos con los mismos predicados primarios y con sintagmas 'de estadio" -dejo de momento al margen su aportación semántica al enunciado- en la misma posición que contenta y disgustado; son, sin embargo, enunciados correctos, al igual que Estos coches duran mucho bien cuidados, Los pisos cuestan más caros nuevos, construidos con la misma clase semántica de predicado.

Tampoco, por poner otros ejemplos, parecen anómalos Somos felices juntos, El chico tiene un aspecto impresionante desnudo, Juan tiene muy mal carácter borracho pero aún lo tiene peor sobrio, La casa presenta un aspecto desolador con las ventanas rotas, y, no obstante, atendiendo a las características que se asocian a sus predicados principales, habría que considerarlos construidos con predicados "auténticamente estativos" en líneas generales:

En Somos felices juntos el predicado principal sería 'de individuo o 'estable', de conformidad, por ejemplo, con Fernández Leborans (1999: 2366), puesto que si bien feliz no denota por sí mismo "una propiedad permanente, ni intrínseca o inherente" ${ }^{33}$, al combinarse con ser atribuye una "cualidad", no "refiere a estadio o episodio" sino a "propiedad". El chico tiene un aspecto impresionante desnudo, Juan tiene muy mal carácter borracho pero aín lo tiene peor sobrio, contienen predicados con el verbo tener "estativo-descriptivo" (Cano Aguilar, 1981: 101) con los que, a juicio por ejemplo de Cano Aguilar (ibid.) o De Miguel (1999: 3013), se indican "cualidades", "características" "propiedades inalienables del sujeto ${ }^{34}$. En cuanto al verbo presentar en La casa presenta un aspecto desolador, se podría agrupar con los verbos que Demonte y Masullo (1999) catalogan como "transitivos espurios" o "semicopulativos" debido a que está utilizado para describir características del sujeto, a semejanza de los predicados con tener "estativo-descriptivo" o los de carácter atributivo.

32 Véase la nota anterior sobre las 'cláusulas reducidas' introducidas por la preposición con.

33 Como indica en otro lugar (Fernández Leborans, 1995b), feliz, como otros atributos que pueden construirse con ser, "puede expresar cambio o evolución que puede alcanzar el sujeto ocasionalmente". De ahí que no considere "afortunada" la distinción "propiedad inherente o permanente" (con ser)/ "propiedad accidental o transitoria" (con estar) para diferenciar los usos atributivos de ser y estar.

También Demonte (1999: 143) comenta que si bien feliz denota "estado", la "disposición de ánimo" designada por el adjetivo se concibe como "cualidad" al formar el predicado con ser y no con estar.

34 Algo quizá más evidente en Tiene muy mal carácter que en Aún lo tiene peor sobrio por la implicación de cambio que conlleva el comparativo peor. Según Zagona (1993:319) "an otherwise stative verb can become eventive on the basis of the interpretation of one of its arguments. For example, a compared object can be temporally distributed, producing an event, or change of state: tener cada dia más información". Asimismo, según De Miguel (1999: 3014), con complementos como cada vez más, en estos días, últimamente, se da a entender que el evento avanza progresivamente: "no son pues homogéneos, sino dinámicos". 
Por lo demás, bien cuidados, nuevos, juntos, borracho, sobrio, con las ventanas rotas, al igual que descalza, desnudo, con los bolsillos vacios, son, como los predicativos adjuntos del sujeto, sintagmas 'de estadio", teóricamente capacitados para denotar una "situación" por el contenido temporal/aspectual ${ }^{35}$ de que están dotados; designan un estado transitorio del sujeto y constituyen, por tanto, un predicado secundario-una predicación defectiva, carente de marcas verbales y dependiente del predicado primario- referido al sujeto y sintácticamente optativo, es decir, 'adjunto', 'no seleccionado'.

Son pues enunciados correctos con un predicado primario 'estativo' y con un predicado secundario - un 'predicativo' en sentido amplio- 'de estadio'. Por tanto, ni la estatividad del predicado principal es la razón de la anomalía de *Maria mide 2 metros contenta, o *Juan pesa poco disgustado, aunque sí pueda serlo de la imposibilidad de una lectura "predicativa pura' para los predicados secundarios, ni tampoco, obviamente, es responsable de la anomalía la clase léxico-aspectual de contenta y disgustado.

Conviene recordar, además, incidiendo en la precaución con que han de tomarse las anomalías por razones 'aspectuales', que para los predicativos no seleccionados en sintagmas nominales -la llegada de Juan borracho, la entrada de Luis vestido de mujer- se han postulado "condiciones de habilitación" idénticas o similares a las que se requieren en las oraciones (Suñer, 1999; Demonte y Masullo, 1999; Leonetti y Escandell, 1991). Mide 2 metros descalza, Pesa 48 kilos desnudo, Tenía un aspecto impresionante desnudo, son, efectivamente, paralelos a sintagmas nominales "gramaticales", "correctos", del tipo las medidas de Miss España desnuda, la altura de Juan descalzo, el aspecto de Ernesto en calzoncillos (Suñer, 1999; Leonetti y Escandell, 1991), que no están constituidos por nombres que denoten acontecimientos -como la llegada de Juan borracho- sino por nombres "intrínsecamente relacionales" porque "suponemos habitualmente" "que son las medidas, el peso o el aspecto de alguien" (Leonetti y Escandell, 1991), lo cual a juicio de Leonetti y Escandell (1991: 440) llevaba a concluir que, para explicar las restricciones de aparición de los predicativos adjuntos -tanto en oraciones como en sintagmas nominales, si se habilitan en condiciones semejantes-, "la noción de evento o acontecimiento" no puede ser la única relevante" ${ }^{\prime 36}$.

\subsection{Predicativos 'condicionales': aspectos de contenido}

Si parece claro que Mide dos metros descalza, Pesa 48 kilos desnudo y el resto de los enunciados estativos que he venido mencionando contienen un predicado secundario 'de estadio' referido al sujeto y no seleccionado, resulta asimismo evidente que su lectura no puede ser la predicativa pura que se asocia a enunciados como Caminaba pensativo, Se marchó disgustado.

35 En opinión de Hernanz (1993: 149), "el que los ADJS libres encabezados por un adjetivo (o participio) puedan adoptar una interpretación adverbial (...) derivaría de su valor aspectual". Según Fernández Lcborans, por el contrario, "en última instancia lo que legitima cualquier tipo de predicado SL como constituyente de una CA es el tiempo, no el Aspecto"; estarian dotados de "tiempo interno, inducido por el Aspecto" (Fernández Leborans, 1995b: 373).

36 De hecho, para justificar la aparición de los predicativos con nombres relacionales se ha apelado al "carácter transitivo de los nombres" (Suñer, 1990: 560) o a "la capacidad del núcleo nominal de seleccionar argumentos" (Leonetti y Escandell, 1991: 440), condiciones evidentemente no aspectuales. 
En ambos tipos de construcciones se da una relación de simultaneidad, de concomitancia temporal, entre el cstado descrito por el predicativo y el predicado primario: Pesa 48 kilos "estando" desnudo, Mide dos metros "estando" descalza, Caminaba "estando" pensativo, Se marchó "estando" disgustado $o^{37}$. Pero es sabido que el sentido de las predicaciones defectivas, sin adverbios introductores u otras "partículas" que orienten su significado, viene en parte ${ }^{38}$ determinado por propiedades del predicado primario y el sentido concreto en que cristaliza esa relación de simultaneidad no puede ser el mismo con un predicado principal eventivo y con un predicado de estado, con las coordenadas temporales relajadas, sin valor temporal específico.

La lectura predicativa pura -Estaba pensativo mientras caminaba, Estaba disgustado cuando se marchó- implica predicados que denotan eventos "que ocurren", que están ligados a una ubicación espacio-temporal y que pueden formar parte de oraciones con "un contenido temporal en sentido estricto" (Fernández Leborans, 1999: 2438) encabezadas ${ }^{39}$ por mientras -"solidario" con predicados que designan 'actividades' y 'realizaciones' (García Fernández, 1999: 3185)- o por cuando, que puede reflejar una lectura inclusiva ${ }^{40}$ del evento en un estado de desarrollo más amplio. No es, por tanto, compatible con predicaciones estativas no vinculadas a una temporalidad específica.

Por el contrario, la lectura que conviene al predicativo en los enunciados "auténticamente" estativos que estamos considerando es la 'condicional' o, por ser más exactos, 'temporal/ condicional' $^{41}$; un tipo de contenido que sí parece acorde con los rasgos de la predicación principal, puesto que en la interpretación de las predicaciones defectivas -como construcciones 'de gerundio', 'adjuntos libres', 'complementos incidentales', 'construcciones absolutas'-, caracterizada por su variabilidad, el sentido condicional se ha venido asociando, además de a la relación de simultaneidad ${ }^{42}$, a la "relajación de las coordenadas temporales", a la ausencia de "valor temporal específico", de "concreción deíctica temporal"43, rasgos sin duda inherentes a la auténtica estatividad.

37 Recuérdese que los predicativos describen un estado del sujeto coincidente con el desarrollo del evento denotado por el verbo (Demonte y Masullo, 1999) o con una fase del evento (De Miguel y Fernández Lagunilla, 2002: 218).

38 Hay que tener también en cuenta otros factores, entre ellos, los de índole pragmática.

39 Tanto mientras como cuando son 'conectores de simultaneidad'. Su uso varía en función de la clase léxicosemántica del predicado principal.

40 Según Garcia Fernández (1999: 3180), en el caso de las construcciones encabezadas por cucundo, "con predicados de estado en la oración principal o en la subordinada, independientemente de la variedad aspectual en que aparezcan, obtenemos la lectura inclusiva".

41 Puesto que en él se imbrican temporalidad y condicionalidad

42 Como señala Narbona (1990: 98), la concomitancia expresada por la simultaneidad temporal se presta fácilmente a "servir de cauce para la expresión de la relación condicional", de ahí la profunda imbricación existente entre las construcciones temporales y las condicionales "en las lenguas del mundo" (Montolío, 1999: 3726). Ha de advertirse, no obstante, que también hay otras interpretaciones sobre el vínculo temporal que favorece la interpretación condicional. Suñer (1990), por ejemplo, la vincula al hecho de que "el tiempo en que transcurre la acción, proceso o cstado designado por el predicado secundario se inscribe en un segmento de ticmpo al de la oración principal". Ausente por motivos de trabajo, Pedro no pudo asistir al bautizo de su hija, Sentados muy juntos creo que cabremos todos, Recién casado te sientes feliz (1990: 66). Entiendo, sin embargo, que la relación en Recién casado te sientes feliz es de simultancidad y lo mismo ocurre en Cabemos todos sentados muy juntos.

43 Según Hernanz (1993: 165), por ejemplo, el valor condicional del 'adjunto libre' en Con este profesor, todo el mundo trabaja, vendría dado por la existencia de un "operador abstracto", no realizado pero realizable léxicamente como siempre (Con este profesor; todo el mundo siempre trabaja), cuya función consiste en "ligar", despojándola de toda concreción deíctica, la referencia temporal aportada por la forma verbal de presentc trabaja, posibilidad que no existe en Con este profesor; todo el mundo trabajó, debido a la temporalidad 'marcada' de trabajó. 
Así pues, el sentido concreto del predicativo en Mide dos metros contenta, Pesa $48 \mathrm{ki}$ los desnudo, y en el resto de los enunciados antes mencionados, es similar al que Halliday (1967) asigna al "conditional attribute" o al que Rapoport vincula a (1993: 164) los "stative depictives" $"$-I like my forniture heavy = I like my forniture (only) if it is hevay-: el estado descrito por el predicado secundario "states the condition of the participant under which the process did or could take place" (Halliday, 1967: 80); se interpreta como condición para que se dé la propiedad -susceptible de cambio "en la realidad"- configurada por el predicado principal: el "medir 2 metros", el "pesar 48 kilos" tiene lugar en coexistencia con el estado descrito por descalza, desnudo, pero no necesariamente si el sujeto se halla en otro estado.

El predicativo se entiende igualmente como condicionante de la variación implicada por la cuantificación comparativa ${ }^{45}$ en Los pisos cuestan más caros nuevos, Tiene peor carácter sobrio, o en Es más temible enfadado, Es casi más coherente borracho. Ese tramo es más peligroso seco, Está mas guapa vestida de rojo/con el pelo suelto, La sopa está más buena fria, enunciados que tampoco imponen una interpretación temporal específica, con independencia de que la construcción con estar o la cuantificación comparativa presupongan un cierto dinamismo por implicar la posibilidad de cambio en la propiedad designada por el estado primario ${ }^{46}$.

Lógicamente, el sentido temporal/condicional queda adecuadamente reflejado en las paráfrasis que hacen explícito el vínculo semántico entre las dos predicaciones condensadas en los enunciados: el predicativo equivale, o bien a una oración condicional, o bien a una oración introducida por cuando, algo que, según Suñer (1990: 66), no siempre es factible con las predicaciones secundarias 'dominadas por Aspecto', pero sí distingue a los predicados secundarios 'dominados por Tiempo'47; es de destacar, no obstante, que las oraciones con cuando a que equivalen estos complementos tienen un valor "restrictivo", no "estrictamente temporal", "cercano semánticamente al condicional" (García Fernández, 1999: 3183) que, según indica Montolío (1999), es el valor que acaba dominando en las oraciones con cuando

44 Predicativos que "are subject to different constraints than stage depictives" (1993: 164). El sentido también es similar, por ejemplo, al que parece tener el predicativo en el enunciado Me gustas callada/ gordita que Demonte y Masullo (1999: 2485) utilizan como ejemplo de predicativo "del objeto" -es de suponer que "del objeto profundo"- "no seleccionado".

45 Fernández Lagunilla (1999) no menciona la cuantificación comparativa como uno de los elementos que favorecen el sentido condicional de las construcciones de gerundio. Pero, curiosamente, el único ejemplo de "gerundio adjunto interno' de sentido condicional que propone contiene un comparativo: Trabaja mejor escuchando música; Trabaja escuchando música sería, en cambio, un gerundio 'modal'.

46 Si las predicaciones estativas se caracterizan, frente a las dinámicas, por no denotar ni implicar 'cambio' es lógico que, como se dijo antes, algunos consideren que, con la cuantificación, la predicación estativa se ha "dinamizado", ya que implica la posibilidad de cambio. En cualquier caso, la interpretación inducida por la temporalidad de estos enunciados es genérica y no vinculada a una ubicación temporal concreta.

47 Además de identificar los predicativos "dominados por Tiempo" por la posibilidad de parafrasearse por una "oración temporal", Suñer (1990:65-66) atribuye a la categoría "Stpo" (Sintagma Tiempo) el hecho de que "algunos de estos elementos puedan funcionar como operadores de valor condicional". Es de advertir, no obstante, que los predicativos que identifica como "dominados por tiempo" no constituyen un conjunto homogéneo. Entre ellos se incluyen los del tipo de joven, de viejo - De joven Juan bailaba estupendamente - y otros de "valor condicional" semejantes a los de nucstros ejemplos: Recién casado, te sientes feliz, (Servida) fría esta sopa no vale nada, para los que, como se indicó en una nota anterior, postula además una relación de anterioridad ("el tiempo en que debe inscribirse la condición debe ser previo al del segmento temporal en que se concreta la acción o el proceso verbal") que no siempre se puede justificar. 
si se "relega" lo puramente temporal": Mide dos metros si/cuando está descalza, Pesa 48 kilos si/cuando está desnudo, Tiene un aspecto impresionante si/cuando está desnudo, Tiene mal carácter si/cuando está sobrio, La sopa está más buena si/cuando está fría, Es más coherente si/cuando está borracho.

Me he centrado en los predicativos condicionales vinculados a predicados primarios léxicamente estativos por ser estos los más comúnmente asociados a la incompatibilidad con los predicativos adjuntos integrados por adjetivos u otros sintagmas 'de estadio'. Pero, dado el carácter composicional de la aspectualidad de los predicados, es evidente que la relajación de las coordenadas temporales, la falta de concreción deíctica temporal, la arquitectura temporal, en definitiva, que propicia o posibilita la lectura condicional, no se limita a los predicados léxicamente estativos. Las mismas condiciones se pueden dar en predicados construidos con verbos léxicamente eventivos - que, por tanto, en otras condiciones, admiten predicados secundarios con lectura "propiamente predicativa"- que pueden, en consecuencia, integrar predicativos de lectura condicional. Tal es el caso, de las "oraciones medias' construidas con verbos que léxicamente expresan eventos (Mendikoetxea, 1999: 1655), como, por ejemplo, limpiar, pero que en presente o imperfecto y "con modificaciones adverbiales", constituyen predicados "de aspecto genérico" (Mendikoetxea, 1999: 1655), en los que las "características temporales quedan obviadas" (Mendikoetxea, 1999: 1663) y, más que acciones, expresan propiedades "atemporales" del sujeto: Estas telas se limpian bien húmedas, La madera se trabaja mejor seca. Es asimismo el caso de enunciados como Uno hace muchas tonterías borracho, Me aburro mucho solo, Nos divertimos más juntos, Este atleta corre mejor descalzo, cuya construcción permite asignarles una interpretación genérica o habitual.

Por lo demás, junto a la "arquitectura temporal"49, hay otros elementos, como los adverbios de 'foco'-únicamente, solo-, o el 'contexto modal' -el auxiliar modal poder o expresiones similares (ser posible) (Fernández Lagunilla, 1999: 3474)-, que se mencionan a propósito de otras predicaciones defectivas como inductores de la interpretación condicional, y que tienen un efecto análogo sobre los predicativos adjuntos integrados por un adjetivo 'de estadio' o por otro tipo de sintagma 'aspectualmente' similar. Así la interpretación condicional parece dominante en Solo existimos despiertos, Este pescado solo está bueno crudo, Solo habla bien con un vaso de vino en la mano, Solo me gusta con el pelo suelto, donde solo focaliza el predicado secundario y excluye, por tanto, que lo significado por la predicación principal tenga lugar cuando el sujeto se halla en otro estado. Igualmente, mientras Conducía por la A-7 completamente borracho, Encestó con los ojos tapados admiten una paráfrasis descriptiva, "propiamente predicativa" -Estaba completamente borracho mientras conducia por la A-7, Estaba con los ojos tapados cuando encestó-, la interpretación condicional domina en No puedes conducir borracho (=No puedes conducir si estás borracho), Es imposible encestar con los ojos tapados (Es imposible encestar si estás con los ojos tapados), con un "contexto modal" que, según Hernanz (1990), actúa "inmovilizándola" sobre la referencia temporal.

48 Eso es lo que sucede, según Fernández Leborans (1999: 2438) en las oraciones introducidas por cuando que contienen "predicados de individuo".

49 En la que habria que incluir la presencia de "tiempos verbales asociados típicamente al periodo hipotético" en la predicación principal (Fernández Lagunilla, 1999: 3477): Estariais más guapos calladitos. 
En cualquier caso, para que la interpretación temporal/condicional sea posible, no solo la característica denotada por el predicado principal ha de ser susceptible de modificación "objetivamente", "en la realidad" -al fin y al cabo, pesar 48 kilos es más modificable que tener los ojos azules, aunque ambos sean predicados de estado; ser feliz es más variable que ser padre, ser de Madrid, aunque la construcción con ser haga que se interpreten como "de propiedad" los predicados-; también ha de darse un vínculo lógico entre las situaciones descritas por los dos predicados; el predicado secundario ha de ser relevante para la variación de la característica configurada por el predicado primario, lo cual nos lleva de nuevo a la anomalía de *Mide 2 metros contenta, *Pesa poco disgustado y al problema de los límites entre las razones semánticas de tipo gramatical y las razones "independientes" de tipo pragmático (Leonetti y Escandell, 1991) cuando hablamos de compatibilidades e incompatibilidades entre predicados.

Así, por ejemplo, según Suñer (1999) y Escandell (1995), las anomalías de *el hermano de Juan borracho, *el padre de María de vacaciones -dos sintagmas nominales con predicados secundarios, teóricamente supeditados a las mismas condiciones que los predicativos oracionales- se deberían a que hermano, padre, como nombres de parentesco, no son susceptibles de variación temporal, a que "resulta incoherente suponer que únicamente mientras está borracho Juan tiene un hermano" (Suñer, 1999: 561) y no "resulta fácil concebir que María tenga un padre cuando está de vacaciones diferente del que tiene cuando no lo está" (Escandell, 1995: 54) ${ }^{50}$; por el contrario, según Suñer (1999) la propiedad de "ser amigo de Félix" sí puede entenderse como "contingente al hecho de estar borracho", de ahí que resulte más aceptable la secuencia los amigos de Félix borracho. Pero deducir de ello que "los nombres hermano o padre [...] son incompatibles desde un punto de vista aspectual con complementos predicativos como borracho o enfermo" (Suñer, 1999: 561) supone desdibujar el contenido de la aspectualidad como categoría pertinente desde el punto de vista gramatical. Para Leonetti y Escandell (1991: 437) son razones de tipo "pragmático" las que explican la anomalía de sintagmas como los anteriormente mencionados o como, por citar otros ejemplos, la pierna de Pepe enfermo, la promesa de Juan descalzo: no es fácil suponer la variación de la pierna ligada a la enfermedad, o concebir la propiedad de "estar descalzo" como un estado relevante para realizar una promesa. Motivos similares, y no la clase léxico aspectual de los predicados, explican, desde mi punto de vista, la anomalía de * María mide dos metros contenta y *Juan pesa poco disgustado: resulta difícil concebir la propiedad de "pesar poco" o de "medir dos metros" como variable en función de si se está "contento" o "disgustado"; en cambio, sí pueden interpretarse como propiedades variables en relación con el hecho de "estar desnudo" o de "estar descalzo".

En definitiva, ni *Mide dos metros contenta o *Pesa poco disgustado resultan anómalos específicamente por la clase aspectual de los predicados, ni los predicados estativos son incompatibles con predicados secundarios adjuntos 'de estadio', aunque sí lo sean con la lectura "propiamente predicativa" que distingue a predicativos adjuntos dependientes de verbos eventivos; al vincularse en una relación de simultaneidad con el estado "transitorio" denotado por un sintagma de estadio, la propiedad que describe el predicado estativo se interpreta como contingente, variable, condicionada a que el sujeto se halle en un estado 
determinado. Tampoco, por último, el sentido temporal/condicional que evidencian los predicativos en este tipo de enunciados depende únicamente de la clase léxico aspectual en que se incluya el verbo aislado; puede ser propiciado por otros rasgos de la construcción, como la arquitectura temporal, que contribuye de manera composicional a configurar la aspectualidad del enunciado.

\subsection{Sobre 'adjuntos libres', 'complementos incidentales' y la ubicación estructural de los predicativos 'condicionales'}

Evidentemente, en la delimitación de los predicativos adjuntos frente a otras categorías de predicaciones defectivas no se hacen intervenir solo aspectos de contenido. Se toma en consideración, asimismo, su posición estructural, vinculada normalmente al contenido y asociada, en planteamientos de corte generativista, a la relación con las categorías funcionales Tiempo y Aspecto. Y el hecho de que los predicados secundarios 'condicionales' sean 'adjuntos', 'no seleccionados', como los predicativos dependientes de predicados eventivos, no garantiza en absoluto que tengan el mismo estatuto sintáctico. Como indica Hernanz (1993: 125) "dentro del cajón de sastre de lo que suele etiquetarse como "complemento no subcategorizados' -nomenclatura que en lo esencial capta, siquiera por vía negativa, el común denominador de los ADJS- existen construcciones de naturaleza muy dispar, cuyas vinculaciones con el predicado verbal distan de ser uniformes". De ahí las propuestas sobre la jerarquización de los "circunstanciales", de difícil solución por el vínculo inextricable que parece haber en este dominio entre semántica y sintaxis.

Los predicativos adjuntos típicos, dependientes de predicados eventivos, se consideran "constituyentes de la cláusula" (Rodríguez Espiñeira, 1990: 270), en "clara conexión" con el verbo (Lapesa, 2000: 260), y eso se traduce formalmente en la ausencia de pausas y en una cierta limitación posicional. De conformidad con Demonte y Masullo (1999: 2482) no tienen tanta libertad de colocación como los 'adjetivos destacados' o 'predicados incidentales'. En el orden normal' ${ }^{51}$-no marcado-del enunciado suelen situarse tras el verbo, sin que medie pausa, bien se coloquen como "adyacentes a él", bien siguiendo "a un complemento argumental suyo, aunque tienden a preceder a los adjuntos circunstanciales", pero, por ejemplo, como indicaba Lapesa, no suelen preceder "a sujeto, objeto y verbo" (Lapesa, 2000: 250) ${ }^{52}$.

Además, según se advierte en numerosos trabajos sobre predicativos, 'adjetivos incidentales' u otros temas vinculados, a veces ${ }^{53}$ basta la "dislocación hacia la posición inicial" o

51 No qujero dar a "orden normal" un sentido técnico específico. Simplemente me refiero a que no resulte un orden extraño o propio de un registro especial. Dada la amplitud y complejidad del tema, además de la falta de acuerdo que preside el uso de los términos relacionados con la estructura informativa y el orden de palabras, no puedo adentrarme en este aspecto. Pero quería destacar al menos que la anteposición no lleva aparejada en este caso la condición de información dada que se asocia a los procesos de "tematización" ni tampoco el relieve fónico propio de los procesos de "focalización", aunque ello no implica que el constituyente "dislocado a la izquierda" no pueda entenderse como información "nueva", como elemento relevante desde el punto de vista informativo.

52 Lapesa, que ya indicaba con respecto a la colocación del predicativo que "lo más frecuente es que vaya a continuación del verbo" (2000: 249), añadía que la anteposición del predicativo "a sujeto, verbo y objeto" solo se registra en poesía o en "prosa muy elaborada" (2000: 250).

53 Digo "a veces" porque según subraya Gutiérrez Ordóñez (1986: 144) hay elementos que no parecen sufrir alteraciones "por $\mathrm{cl}$ simple hecho de colocarlos entre pausas". Hay que tener también en cuenta, como advertía Lapesa (2000: 260), quc, dado el uso que hacen los escritores de la puntuación, el "margen de interpretación puede ser muy grande" y no siempre es fácil distinguir el adjetivo incidental y el predicativo. 
la "colocación entre pausas" para que un predicativo del sujeto pierda su condición de tal. Así, por ejemplo, de conformidad con Fernández Leborans (1995b: 367) en Juan se marchó nervioso por lo sucedido, el constituyente destacado es un predicativo que "predica una actitud del sujeto en relación con la actividad denotada por el verbo", pero en Nervioso por lo sucedido, Juan se marchó, ya no es un complemento predicativo sino una "cláusula absoluta" con un contenido diferente -ahora es "causal"- y un estatus sintáctico distinto -es un elemento "ad-oracional"-; otro tanto ocurriría con el predicativo ${ }^{54}$ de La gente dormía confiada, convertido en un "inciso de significación causal" (Gutiérrez Ordóñez, 1986: 144) en Confiada, la gente dormía, merced al cambio "a posición inicial", o con el de Los muchachos no miraban temerosos a su madre que, debido a su colocación como inciso, pasa a ser "adjetivo destacado", según Porroche (1990: 156), en Los muchachos, temerosos, no miraban a su madre.

Los predicativos 'condicionales', sin embargo, no solo pueden aparecer pospuestos al predicado, sino también como incisos- María, descalza, mide dos metros, El chico, desnudo, tiene un aspecto impresionante-o en posición inicial de enunciado-Descalzo, mide dos metros, Juntos, somos muy felices, Con las ventanas rotas la casa presenta un aspecto desolador-, sin que medie un proceso de focalización o el orden resulte extraño, ni el contenido temporal/condicional se vea necesariamente modificado. Juan, desnudo, pesa 48 kilos, Desnudo, Juan pesa 48 kilos, Juan pesa 48 kilos desnudo, vienen a decir "lo mismo" 55 , aunque respondan a diferentes estrategias desde el punto de vista informativo: 'Juan pesa 48 kilos si/cuando está desnudo'.

Su "sintaxis" es, pues, distinta de la que se asocia a los predicativos 'adjuntos' típicos. Es más, por la posibilidad de aparecer como inciso, por la libertad posicional, que apunta a un estatus más periférico ${ }^{56}$, se podría pensar que tienen más en común con los constituyentes que se catalogan como 'adjuntos libres' ${ }^{57}$, 'adjetivos' o 'complementos incidentales'

\footnotetext{
54 Gutiérrez Ordóñez (1986), de quien he tomado el ejemplo, utiliza el término 'atributo' y no 'predicativo', ya que no emplea términos diferentes para los elementos que denotan una relación de atribución apoyados en un verbo copulativo y los que la expresan formando parte de una predicación secundaria dependiente de un verbo copulativo. No obstante, sigo empleando el término 'predicativo', tal como dije al principio, para referir a un 'predicado secundario', mientras que 'atributo' lo reservo para el elemento que atribuye una característica formando con el verbo un solo predicado, un predicado complejo.
}

55 Es lo que sugierc Gutiérrez Ordóñez (1997b: 77) con respecto a construcciones condicionales y concesivas que pueden ir pospuestas sin pausas o antepuestas y "parapetadas" tras la estructura formal del inciso: Lo verás si vienes a las ocho, Si vienes a las ocho, lo verás. En este proceso, comenta, "apenas se ha producido una modificación del contenido representativo", las secuencias "vienen a decir lo mismo".

56 Para Halliday (1967) es dudoso que el "conditional attribute" sea un constituyente de la cláusula, aunque tampoco se pronuncia claramente sobre su estatus.

57 Véase, entre otros, Hernanz, 1993; Hernanz y Suñer, 1999. Los adjuntos libres son, según Hernanz, elementos de estatus sintáctico "extraoracional" y de valor "proposicional". Por ejemplo, en Maria estudia en París, Juan trabajó con este profesor, en Paris sería, según Hernanz, un complemento locativo ("María estudia y ello se produce en París") y con este profesor sería un comitativo ("Trabajó con este profesor y no con aquel otro). Pero en Con este profesor, todo el mundo trabaja, con este profesor sería un 'adjunto libre' con valor 'proposicional': Estando con este profesor, todo el mundo trabaja, y lo mismo sucedería con en París en el enunciado En Paris, Maria estudia $=$ Cuando María está en París, estudia

58 Véase, entre otros, Suñer, 1999; Lapesa, 2000; Porroche, 1990. 
"construcciones absolutas ${ }^{59}$ sin sujeto expreso o no bimembres ${ }^{60}$; categorías de predicaciones defectivas cuyos rasgos diferenciadores se cifran en una interpretación "adverbial" o "circunstancial" "1 que, dependiendo del "contexto", de la "arquitectura temporal", de la "posición", se puede concretar como condicional's2; el carácter externo a la predicación

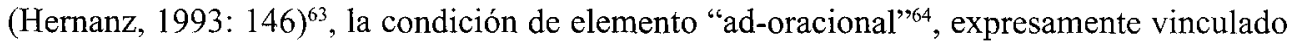
a la interpretación "adverbial; $y$, como rasgos formales indicadores de esa marginalidad, la entonación entre pausas y la libertad posicional: pueden aparecer en posición inicial sin ajustarse "ni a los patrones básicos de la tematización, ni a los de la focalización" (Hernanz, 1993: 144), interrumpir la oración como un paréntesis, o "añadirse después" (Lapesa, 2000: 260).

Ciertamente, antepuestos o como incisos, los predicativos 'condicionales' de nuestros enunciados, por la posición, la entonación entre pausas, la clase aspectual, el contenido que los vincula al predicado primario, resultan semejantes a otros sintagmas 'de estadio', depen-

\section{Véase, entre otros, Gutiérrez Ordóñez, 1986, 1997; Fernández Leborans, 1995b; Marín Gálvez, 2000.}

60 Fernández Leborans (1995b: 366), recuerda que "una de las propiedades distintivas de las cláusulas absolutas destacadas por la tradición gramatical es que deben poseer un sujeto léxico independiente", sin embargo, añade, "no parece haber razón alguna para no considerar absolutas aquellas construcciones en las que el sujeto, tácito o expreso, es correferencial con el sujeto o con el objeto del verbo principal". Para Gutiérrez Ordónez "las construcciones absolutas y los adjetivos o sustantivos incidentales son variantes de la misma construcción", "Ia única diferencia clara y patente entre las incidentales y las absolutas clásicas se halla en la localización del tema: en las construcciones absolutas propias el tema se parapeta dentro del inciso y no suele ejercer función alguna dentro de la oración a la que el inciso modifica. Caso de contraer alguna función, habrá de estar reproducido por un elemento pronominal. Por el contrario, en las incidentales el tema se halla siempre extramuros, como funtivo del esquema sintagmático que hospeda el inciso" (1997, 330: 1986: 152).

61 Siempre que sean sintagmas 'de estadio'. Introduzco esta restricción porque los elementos que se clasifican como 'adjuntos libres' o 'complementos incidentales', no son realmente homogéneos. Hernanz y Suñer (1999: 2547) indican que los adjetivos que denotan 'estadios' ofrecen menos resistencia para aparecer como 'adjuntos libres' que los que designan "propiedades individuales". Así, por ejemplo, según Hernanz (1993: 149) *Francesas, las patatas son buenas es anómalo por el carácter "no perfectivo" de francesas, lo cual implica que carece de un "argumento eventivo" y, "por consiguiente" de "fuerza para adoptar un valor cuasi-proposicional". Pero lo cierto es que como 'adjuntos libres' o "complementos incidentales' también se incluyen, según reconocen Hernanz y Suñer, elementos que "carecen de valor perfectivo" (Hernanz y Suñer, 1999: 2547) que parecen más aceptables, sin que se explique por qué, si la construcción se incrementa "mediante el recurso a la coordinación o a algún complemento", como, según sus ejemplos, sucede con los adjetivos de Julia, inteligente y precavida, cerró la puerta (ibid.), frente a ?? Julia, inteligente, resolvió el problema.

62 De hecho el valor 'condicional' de estas y otras predicaciones defectivas se suele vincular a la ubicación de los constituyentes en la periferia oracional y "con frecuencia" (Gutiérrez Ordóñez, 1986: 148) a la posición inicial de enunciado. Según Rodríguez Espiñeira, por ejemplo, la predicación secundaria que expresan los adjetivos incidentales, en posición inicial, "puede mantener relaciones semánticas diversas con la predicación principal: temporal, concesiva, condicional, etc." (1990: 270). También Fernández Leborans destaca el condicional como uno de los valores de la 'construcción absoluta', generalmente "situada en posición inicial por la determinación (temporal, causal, condjcional o concesiva) que ejerce sobre la oración principal"(1995: 365). Desde el punto de vista de Hernanz, el contenido condicional es uno de las valores básicos de los 'adjuntos libres', que, según sus términos, comparten en virtud de su carácter periférico "el estatus de 'tópicos' o 'temas' con las oraciones condicionales" (1993: 166). En Con este profesor, todo el mundo trabaja, tendriamos, pues, un 'adjunto libre' de sentido condicional vinculado a esa posición.

63 Ya Lapesa señalaba que el adjetivo incidental no constituye propiamente un complemento del verbo sino una "suboración autónoma condensada" (2000: 260).

64 En términos de Fernández Leborans (1995b: 367), una construcción absoluta aunque tenga un sujeto correferencial, no se adjunta a un constituyente de la oración principal, sino a la oración principal, por eso considera que "no son cláusulas adverbiales sino ad-oracionales". 
dientes asimismo de predicados de estado --con un 'contexto modal' en algunos casos-, que, en distintos trabajos, se han tipificado como 'adjuntos libres', 'construcciones absolutas' o 'complementos incidentales'. Es, por ejemplo, el caso de los constituyentes destacados en los siguientes enunciados: Irritado, Juan resulta insoportable, Hervidas, las acelgas pueden resultar apetitosas, Cocidas, las patatas están buenas, Dormidos, los niños son un encanto, 'adjuntos libres' según Hernanz (1993, véase también Hernanz y Suñer, 1999), Vestida de negro, pareces más alta, un 'complemento incidental' para Suñer (1999), o La piscina, vacía, parecía más grande, una 'construcción absoluta' desde el punto de vista de Marín Gálvez ${ }^{65}$ (2000).

Prescindo, puesto que no son mi objetivo específico, de los problemas ${ }^{66}$ propios de los 'adjuntos libres', 'complementos incidentales' o 'construcciones absolutas' (no bimembres), etiquetas distintas que, no obstante, como se habrá inferido por los anteriores ejemplos, se utilizan para elementos -y conceptos- que, al menos en los rasgos mencionados, parecen coincidentes ${ }^{67}$ y que voy a emplear como si fueran equivalentes.

Pero sí he de señalar que no solo los predicativos 'condicionales' de nuestros ejemplos sino tampoco los elementos destacados en los ejemplos de Hernanz, Suñer, o Marín Gálvez se ajustan del todo a los rasgos formales y sintácticos que se asocian a los 'adjuntos libres' o 'complementos incidentales' y que permiten considerarlos elementos "ad-oracionales", externos a la predicación, absolutamente periféricos, sea cual sea el lugar que ocupen en el enunciado.

65 En realidad, lo considera una construcción absoluta predicativa, pero incluye los incisos en esta categoría.

66 Dejando incluso al margen los cuestiones planteadas en torno a la 'función incidental' (véase Gutiérrez Ordóñez, 1997; Fernández Fernández, 1993; Martínez, 1994), cabe ya de entrada señalar que estas etiquetas abarcan elementos que comparten algún rasgo formal, como la "estructura del inciso", pero con diferencias semánticas y de "comportamiento" más o menos ligadas, según señala Suñer (1999: 545) a las "categorías sintagmáticas". Así, por cjemplo, la libertad de colocación que suele asociarse a estos elementos, no sería, de conformidad con Suñer, aplicable a todas las categorias: "los participios (y, en menor medida, los adjetivos), evidentemente relacionados con construcciones absolutas, gozan de mayor libertad de ubicación que los nombres". Tampoco se podría hablar de valores semánticos comunes dada la variedad de elementos que en nuestros estudios gramaticales se han incluido en estas clases; y no me refiero solo a la variedad de "interpretaciones adverbiales" que, dependiendo del contexto, pueden adoptar. Me refiero también a que, por ejemplo, no siempre se les puede asociar el "valor (cuasi)proposicional", vinculado a su valencia temporal/aspectual, que atribuye a los "adjuntos libres" Hernanz (1993: 128). Como también señalan Hernaz y Suñer (1999) en otro lugar muchos de los adjetivos que pueden concurrir como adjuntos libres carecen "de la interpretación temporal que es habitual en las CCAA y adoptan una lectura semánticamente neutra, más próxima a las relativas explicativas que a las subordinadas adverbiales". Así en El novio, vestido para la ocasión, llegó puintual el participio incidental se presta, desde mi punto de vista, a una paráfrasis "meramente descriptiva" y lo mismo ocurriria, según Hernanz y Suñer en Aterido por el frío, el borracho hablaba solo en una esquina. Marín Gálvez (2000: 238) incluye en la misma categoría, la de las construcciones absolutas aspectuales, los elementos incidentales de "Esta ropa, muy de moda últimamente, se vende como rosquillas" que, desde mi punto de vista, tendría una interpretación descriptiva y "Este cuadro, arriba, se vería mejor" que condiciona el valor de verdad de la oración. Al fin y al cabo, como advierte Gutiérrez Ordóñez, "el inciso y la anteposición son estrategias del discurso que en sí mismas no tienen encomendada ninguna función sintáctica ni contenido semántico fijo y estable" (1986: 148).

67 Hernanz y Suñer (1999: 2546), por ejemplo, equiparan 'adjuntos libres' y 'adjetivos o complementos incidentales'; para Gutiérrez Ordóñez, como se señaló antes, los atributos incidentales no son si no construcciones absolutas "con el tema extraditado, por imperativo legal, a los feudos de la oración en la que también contrae una función" (1997: 331), aunque para Suñer y Hernanz los "adjuntos libres" no son meras variantes de las construcciones absolutas porque la "extensión de aquellos abarca dominios en que no hay solapamiento posible" con las construcciones absolutas (1999: 2547), identificando como tales a las "bimembres". 
Recordemos, en primer lugar, que los rasgos formales que se destacan como marca distintiva de su estatus "ad-oracional", "periférico" ${ }^{68}$, son la libertad posicional y la inflexión melódica, ya aparezcan en posición inicial, ya como incisos o pospuestos al verbo.

Las pausas acompañan, en efecto, sea cual sea su posición, al "complemento incidental" -que además de acompañar a un predicado 'eventivo' es, a mi juicio puramente descripti$\mathrm{vo}^{69},-$ destacado en Vestido para la ocasión, el novio llegó puntual a la cita (Suñer, 1999: 545): El novio, vestido para la ocasión, llegó puntual a la cita, El novio llegó puntual a la cita, vestido para la ocasión. Asimismo, para Hernanz, puesto que los 'adjuntos libres' conservan en cualquier posición la "inflexión melódica" que los distingue, los predicativos condicionales de Cocidas, las patatas están buenas, Dormidos, los niños son un encanto, conservarían la inflexión melódica que los distingue si se trasladaran al final de enunciado: Las patatas están buenas, cocidas, Los niños son un encanto, dormidos ${ }^{70}$.

Los sintagmas 'de estadio' de nuestros enunciados, en cambio, pueden aparecer en posición inicial de oración o interrumpiéndola como un paréntesis, pero no van entre pausas, como se ha visto, cuando se posponen al verbo. Lo que corresponde a Desnudo, Juan pesa 48 kilos, Descalzo, mide dos metros, etc. es Juan pesa 48 kilos desnudo, Mide dos metros descalzo, y no Juan pesa 48 kilos, desnudo, Mide dos metros, descalzo. Pero estimo que lo mismo sucede con Cocidas, las patatas están buenas, Dormidos, los niños son un encanto, o con Irritado, Juan resulta insoportable, Hervidas, las acelgas pueden resultar apetitosas, Vestida de negro, pareces más alta, La piscina, vacia, parecía más grande. Se corresponden con Juan resulta insoportable irritado, Las acelgas pueden resultar apetitosas hervidas, Los niños son un encanto dormidos, Las patatas están buenas cocidas, Pareces más alta vestida de negro, La piscina parece más grande vacía, sin pausa ante el elemento destacado, al igual que los predicativos 'condicionales' de nuestros enunciados.

Las pausas, a mi juicio, convertirían a estos sintagmas en un 'apéndice' correctivo - un mecanismo propio de la lengua hablada "no planificada"-; en un constituyente que, en términos de Dik (1997, 2: 401), añade "bits of information which may be relevant to a correct understanding of the clause", que proporciona "some additional information pertaining to the proper interpretation of the clause" (Dik, 1997, II: 401) y que, en consecuencia, el hablante considera relevante enunciar, pero que no estaba previsto "en su plan discursivo inicial"71. Así en Mide dos metros, descalzo, Las acelgas están buenas, cocidas, descalzo, cocidas, serían 'apéndices' que corrigen el enunciado anterior aportando el valor restrictivo necesario para su correcta interpretación: no mide dos metros en cualquier circunstancia; solo si está descalzo; las acelgas no están buenas siempre, de cualquier manera; la propiedad

68 Como señalaba Lapesa con respecto a los "adjetivos incidentales", la libertad de colocación y la separación entre pausas marcan formalmente la autonomía con respecto al resto de la frase. También Hernanz, por citar un ejemplo más (1993: 140), indica que el "estatus periférico" de los adjuntos libres está estrechamente vinculado al hecho de que vayan separados por medio de una inflexión melódica.

69 Esto es, con esa lectura semánticamente neutra, más próxima a las relativas explicativas que a las subordinadas adverbiales, que tienen algunos complementos incidentales según Hernanz y Suñer (1999).

70 En todos los ejemplos de Hernanz la "inflexión melódica" se da tanto si estos elementos ocupan la posición inicial como si se posponen al sintagma verbal. Según indica en nota (1993: 126) "Todo el mundo trabaja con este profesor" solo admite una interpretación idéntica a "Con este profesor, todo el mundo trabaja" en cl caso de que entre con este profesor y el resto de la oración se produzca una pausa.

71 Como dice Montolío (1999: 3654) a propósito de las oraciones condicionales pospuestas "con pausa". 
de "estar buenas" solo les corresponde si están cocidas. Y así para el resto de los ejemplos que se han mencionado.

Tampoco parece que pospuestos al verbo sin pausas se les pueda atribuir otros rasgos de comportamiento vinculados a la condición de elementos marginales, externos a la oración.

De 'adjuntos libres', 'construcciones absolutas', 'complementos incidentales', se dice, por ejemplo, que quedan fuera del alcance de la negación, o de otros elementos dotados con parecidas propiedades de ámbito (Hernanz, 1993) ${ }^{72}$, tanto "en posición preverbal como en posición postverbal" (Hernanz y Brucart, 1987: 269). Así, según Hernanz (1993: 145) con este profesor, en calidad de adjunto libre, es "del todo inmune a los efectos de la negación" tanto en Con este profesor, los alumnos no estudian (... pierden el tiempo miserablemente), como en Los alumnos no estudian, con este profesor (... pierden el tiempo miserablemente). En cambio la negación si afectaría, pongamos por caso, al predicativo adjunto, vinculado al verbo, de Juan no llegó exhausto (=sino fresco como una rosa).

Los sintagmas de estadio de nuestros enunciados han de quedar, lógicamente, fuera del ámbito de la negación cuando aparecen en posición inicial o como incisos-Húmedas, estas telas no se limpian bien, Juan, desnudo, no pesa 48 kilos-, puesto que, de conformidad con Sánchez López (1999: 2577), no se puede interpretar como foco de la negación ningún elemento antepuesto. Pospuestos al verbo con pausas seguirían siendo 'apéndices' correctivos, solo que de un enunciado negativo: Maria no mide dos metros, descalza (con tacones de 15 centímetros puede que si); pero, desde luego, no son "del todo inmunes" a los efectos de la negación cuando se posponen al verbo sin que medie pausa entre ellos: en No mide dos metros descalza, No tiene mal carácter borracho, La piscina no parece más grande vacía, No pareces más alta vestida de negro, Estas telas no se limpian bien húmedas, el adjetivo puede entenderse como foco de la negación en calidad de "responsable de la falsedad o inadecuación de la frase con la realidad" (Sánchez López, 1999: 2577). Podrían, en secuencia, ser el foco de una "negación adversativa" de carácter correctivo: No pesa 48 kilos vestido sino desnudo, No pareces más alta vestida de negro sino vestida de rojo, Las telas no se limpian bien húmedas sino secas. Y todo ello, además de poner de manifiesto su condición de "información nueva"73, su "relevante valor informativo"7 , puede considerarse indicativo de que, al menos en esta posición, no son exactamente adjuntos "ad-oracionales", elementos "extrapredicativos".

En la misma dirección apunta el hecho de que puedan ser el foco de adverbios 'delimitadores" - Las acelgas solo están buenas hervidas-; que admitan una "confrontación disyuntiva" en un enunciado interrogativo o que sean focalizables mediante una construc-

72 También Porroche (1990: 156) señala que la negación no afecta al "adjetivo destacado", aunque sí al predicativo: Los muchachos, temerosos, no mirahan a su madre, Los muchachos no miraban temerosos a su madre. Igualmente Rodriguez Espiñeira (1991: 270) indica refiriéndose a los adjetivos incidentales y los predicativos, que "su integración en la cláusula puede comprobarse acudiendo a la negación, que afecta a toda la predicación compleja que contiene el predicativo, en cambio, cuando el adjetivo destacado sigue al sustantivo en la frase, la negación de la predicación no incluye la negación de la predicación expresađa por el adjetivo".

73 Según Gutiérrez Ordóñez (1997b: 27), "solo el elemento conformado por el hablante como información nueva permite la negación adversativa No $A$ sino $B$ ". Asimismo Sánchez López señala que el sintagma correctivo encabezado por sino introduce "un nuevo eiemento de naturaleza remática" (1999: 2577).

74 Según Porroche (1990: 156) el "relevante valor informativo" o "alta jerarquía remática" diferencia al predicativo del adjetivo destacado. Rodríguez Espiñeira, sin embargo, no comparte este punto de vista. 
ción ecuacional, características ambas que, según Gutiérrez Ordóñez, discriminan "circunstantes" -marcados por su "exterioridad" (1997: 373)- y "aditamentos" que afectan a la unidad que forma con sus constituyentes el verbo (ibid.): ¿Parece más alta vestida de negro o vestida de rojo? ¿Pesa 48 kilos vestido o desnudo? Vacia es como parece más grande la piscina, Húmedas es como se limpian bien estas telas, Cocidas es como resultan buenas las acelgas, etc.

Puede deducirse, por tanto, que las diferencias que se asocian a la ubicación y a las posibilidades entonativas de estos predicados secundarios responden básicamente a las pautas de colocación y de "inflexión" que, por ejemplo, Montolío (1999) y Gutiérrez Ordóñez (1997) atribuyen a las oraciones condicionales.

Pospuestos y con pausas, expresan, como las prótasis condicionales con un patrón melódico semejante-Me voy a comprar un coche, si me pagan lo que me deben-, "una idea tardia" que el hablante añade para que "modifique o enmiende lo anterior a modo de autoenmienda o rectificación a posteriori" (Montolío, 1999: 3654).

La posposición sin pausas corresponde a una estructura no topicalizada en la que el condicional, 'adjunto', pero no externo, se inscribe en el nivel ${ }^{75}$ combinatorio de los adjuntos internos o, en términos de Gutiérrez Ordóñez, de los 'aditamentos', y viene a expresar una restricción o modificación semántica respecto de la cláusula principal (Montolío, 1999: 3654).

La posición inicial, el inciso ${ }^{76}$, serían rasgos propios del nivel más externo -el de los 'circunstantes'- en el que se ubican las unidades condicionales cuando se seleccionan como 'tópico'; esto es, cuando establecen "el marco con respecto al cual se interpreta la información que sigue" (Montolío, 1999: 3654).

Son, pues, posibilidades de colocación y de "inflexión" que responden a estrategias diferentes en la planificación informativa; al hecho de que se pueda asignar a estos predicados secundarios funciones informativas distintas, asociadas, a su vez, a propiedades sintagmáticas distintas. Pero, aunque sí hay otros complementos ${ }^{77}$ - instrumentales', "comitativos "...- que "adaptan" su contenido al "saltar" al nivel de los "tópicos o circunstantes" (Gutiérrez Ordóñez, 1997: 402), "en el caso de las condicionales" esa transformación de orden informativo no suele ir acompañada de "una modificación de contenido" representativo (ibid.).

Por consiguiente, el contenido temporal/condicional de Pesa 48 kilos desnudo, Mide 2 metros descalzo, etc., conformado por la "arquitectura temporal", el contexto modal, las propiedades semánticas intrínsecas del predicado secundario, no depende de la posición inicial, ni de la inflexión melódica ni, en definitiva, de la marginalidad.

Quizá en la ordenación estructural de los adjuntos, en la que se imbrican sintaxis y semántica de forma inextricable, estos predicados secundarios de contenido temporal/

75 Para Gutiérrez Ordóñez (1997), ni 'aditamentos' ni 'circunstantes' constituyen funciones sintácticas del tipo 'sujeto', 'objeto directo'; se trata de "niveles de inserción", de "órbitas" en las que se insertan varias funciones.

76 Como advierte Gutiérrez Ordóñez (1997b: 49), la función informativa 'tópico' no siempre se identifica con la posición inicial absoluta.

77 Como el caso, ya mencionado, de los predicativos "típicos": Los chicos no llegaron cansados, Cansados, los chicos no llegaron.

78 Por ejemplo, No trabajo con la tele encendida, Con la tele encendida, no trabajo; No llegarán con Luisa, Con Luisa. no llegarán. 
condicional sean -como, en general, se atribuye a los "predicativos dominados por Tiempo ${ }^{79}$ - más externos que los predicativos típicos, caracterizados por Suñer (1990) como 'dominados por Aspecto'. Así parece indicarlo la mayor libertad de colocación o el hecho de que, de coexistir dos predicados secundarios referidos al mismo sujeto, el valor temporal condicional se asocie de modo más claro al "externo": Jugaba feliz, Jugaba descalza, Solo jugaba feliz descalza.

Pero si bien su sintaxis no se ajusta a la de los predicativos típicos que dependen de predicados eventivos, parece claro que tampoco coincide, en realidad, con la de esos constituyentes que, en cualquier posición, van acompañados de la inflexión melódica y de los rasgos de comportamiento asociados a la condición de elementos "ad-oracionales", externos, extrapredicativos. Utilizando la distinción de Gutiérrez Ordóñez, habría que considerarlos al menos 'aditamentos', 'adjuntos internos', aunque puedan 'topicalizarse' y "saltar" a un nivel más externo.

\section{Para concluir}

Estas notas sobre el sentido de los predicados secundarios adjuntos, orientados al sujeto, de Mide dos metros descalza, Pesa 48 kilos desnudo, Estas telas se limpian bien húmedas, etc.; sobre los rasgos de los predicados primarios que se pueden asociar a su interpretación 'condicional'; sobre su carácter más o menos marginal, sus diferencias y semejanzas con otras categorías de predicaciones secundarias, son únicamente unos apuntes, algunos datos, que, obviamente, no permiten formular generalizaciones sobre los condicionamientos de la interpretación temporal/condicional, o restricciones de coaparición como las que se han ido formulando en las últimas décadas para otros tipos de predicados sècundarios, tomando como base los vínculos de índole léxico-aspectual entre los dos predicados. Pero tampoco, como indicaba al principio, era ese el objetivo planteado.

Solo pretendía comentar peculiaridades de unos predicados secundarios que no alcanzaba a encuadrar en ninguno de los tipos de complementos predicativos más comúnmente admitidos, ni tampoco en otras categorías, distintas en principio, pero próximas a los predicativos por representar predicaciones defectivas integradas por adjetivos o por otros tipos de sintagmas con un potencial similar como predicativos; unos predicados secundarios que, en definitiva, parecen constituir otro tipo, con otro contenido, otros condicionamientos, otra sintaxis, dentro de esa "gran bolsa" que son las predicaciones secundarias de carácter atributivo, sobre la que, como sugería también al principio, por su amplitud y complejidad, difícilmente podría estar todo dicho, ni en materia de tipos, ni de condicionamientos o de valores de contenido.

\section{Referencias bibliográficas}

Alarcos Llorach, E. (1994): Gramática de la lengua española, Madrid, Espasa Calpe. Alcina Franch, J. y J. M. Blecua (1975): Gramática española, Barcelona, Ariel.

79 Obsérvese que también algunos predicativos "dominados por Tiempo", para los que se postula un "estatus periférico" aparecen sin la "estructura formal del inciso" cuando se posponen al verbo: De joven Juan bailaba estupendamente, Juan, de joven, bailaba estupendamente, Jian bailaba estupendamente de joven. 
Bosque, I. (1990): "Sobre el aspecto en los adjetivos y en los participios", en Bosque I. (ed.), Tiempo y aspecto en español, Madrid, Cátedra, págs. 177-211.

Bosque, I. y V. Demonte (dirs.) (1999): Gramática Descriptiva de la Lengua Española, Madrid, Espasa.

Cano Aguilar, R. (1981): Estructuras sintácticas transitivas en el español actual, Madrid, Gredos.

De Miguel, E. (1999): "El aspecto léxico", en Bosque, I. y V. Demonte (dirs.), págs. 2977-3060.

De Miguel, E. y M. Fernández Lagunilla (2000): "El operador aspectual se", Revista Española de Lingüistica, 30, 1, págs. 13-43.

De Miguel, E. y M. Fernández Lagunilla (2002): "Predicación secundaria y modificación adverbial", en Actas del II Congreso de la Sociedad Española de Lingüistica (Madrid 11-15 diciembre 2000), Vol. II, Madrid, Gredos, págs. 218-225.

De Miguel, E. y M. Fernández Lagunilla (2003): "Un enfoque subeventivo de la relación entre predicados secundarios y adverbios de manera", Revue Romane (en prensa).

Demonte, V. (1991): Detrás de la palabra, Madrid, Alianza.

Demonte, V. (1999): "Semántica composicional y gramática: Los adjetivos en la interficie léxico-sintaxis", Revista Española de Lingüística, 29, 2, págs. 283-316.

Demonte, V. y P. J. Masullo (1999): "La predicación: Los complementos predicativos", en Bosque, I. y V. Demonte (dirs.), págs. 2461-2523.

Dik, S. C. (1997): The Theory of Functional Grammar, Part 2, Berlín, Nueva York, Mouton de Gruyter.

Escandell Vidal, M. V. (1995): Los complementos del nombre, Madrid, Arco Libros.

Fernández Fernández, A. (1993): La función incidental en español. Hacia un nuevo modelo de esquema oracional, Oviedo, Universidad de Oviedo.

Fernández Lagunilla, M. (1999): "Las construcciones de gerundio", en Bosque, I. y V. Demonte (dirs.), págs. 3443-3503.

Fernández Lagunilla, M. y E. de Miguel (2001): "Más allá de la información subeventiva: procesos que operan con los qualia de los nombres", XXXI Simposio de la Sociedad Española de Lingüística.

Fernández Leborans, M. J. (1995): "Las construcciones con el verbo estar: aspectos sintácticos y semánticos", Verba, 22, págs. 253-284.

Fernández Leborans, M. J. (1995b): "Sobre construcciones absolutas", REL, 25:2, págs. 365-395.

Fernández Leborans, M. J. (1999): "La predicación: Las oraciones copulativas", en Bosque, I. y V. Demonte (dirs.), págs. 2357-2460.

García Fernández, L. (1999): "Los complementos adverbiales temporales. La subordinación temporal", en Bosque, I. y V. Demonte (dirs.), págs. 3129-3208.

Gili Gaya, S. (1961): Curso superior de sintaxis española, Barcelona, Biblograf.

Gutiérrez Ordóñez, S. (1986): Variaciones sobre la atribución, León, Universidad de León.

Gutiérrez Ordóñez, S. (1997): La oración y sus funciones, Madrid, Arco Libros.

Gutiérrez Ordóñez, S. (1997b): Temas, remas, focos, tópicos y comentarios, Madrid, Arco Libros.

Halliday, M. A. K. (1967): "Notes on Transitiviy and Theme in English", I, Journal of Linguistics 3 , págs. 37-81.

Hernanz, M. LL. (1988): "En torno a la sintaxis y la semántica de los complementos predicativos en español", Estudi General 8, págs. 7-27.

Hernanz, M. LL. (1990): "En torno a los sujetos arbitrarios: La 2." persona del singular", en Demonte, V. y B. Garza (eds.) (1990), Estudios de Lingüística de España y México, México, UNAM y EI Colegio de México, págs. 161-178.

Hernanz, M. LL. (1993): “A propósito de los adjuntos libres", en Viana, A. (ed.) (1993), Sintaxi Teoria i Perspectiva, Lleida, Pages Editors, págs. 125-173.

Hernanz, M. LL. y J. M. Brucart (1987): La sintaxis, Barcelona, Crítica. 
Hernanz, M. LL. y A. Suñer Gratacós (1999): "La predicación: La predicación no copulativa. Las construcciones absolutas", en Bosque, I. y V. Demonte (dirs.), págs. 2525-2560.

Laca, B. (1999): "Presencia y ausencia de determinante", en Bosque, I. y V. Demonte (dirs.), págs. 891-928.

Lapesa, R. (2000): "Sintaxis histórica del adjetivo calificativo no atributivo", en Lapesa, R. Estudios de Morfosintaxis histórica del español, editado por R. Cano Aguilar y M. T. Echenique Lizondo, Madrid, Gredos, págs. 235-271.

Leonetti, M. y Escandell, M. V. (1991): "Complementos predicativos en sintagmas nominales", Verba 18, págs. 431-450.

Marín Gálvez, R. (2000): El componente aspectual de la predicación, Tesis doctoral, Universitat Autònoma de Barcelona.

Martínez, J. A. (1994): Cuestiones marginadas de Gramática Española, Madrid, Istmo.

Martínez Álvarez, J. (1985): "Sobre algunas estructuras atributivas", en Lecciones del I y II Curso de Lingüistica Funcional (1983 y 1984), Oviedo, Universidad de Oviedo.

Mendikoetxea, A. (1999): "Construcciones con se: Medias, pasivas e impersonales", en Bosque, I. y V. Demonte (dirs.), págs. 1631-1722.

Montolío, E. (1999): "Las construcciones condicionales", en Bosque, I. y V. Demonte (dirs.), págs. 3643-3737.

Narbona Jiménez, A. (1990): Las subordinadas adverbiales impropias en español (II), Málaga, Ágora.

Navas Ruiz, R. (1977): 'Ser'y 'estar'. El sistema atributivo del español, Salamanca, Almar.

Penadés, I. (1991); "Construcciones atributivas del español en el discurso", Verba, 18, págs. 451468.

Pilkkänen, L. (2000): "On Stativity and Causation”, en Tenny, C. J. Pustejovsky (eds.) Events as grammatical objects, Stanford, CSLI; págs. 417-444.

Porroche Ballesteros, M. (1990): Aspectos de la atribución en español, Zaragoza, Pórtico.

Rapoport, T. R. (1992): "Stage ad Adjunct Predicates: Licensing and Structure in Secondary Predication Constructions", en Reuland, E. y W. Abraham (eds.) Knowledge and language, Volume II, Lexical and Conceptual Structure, Dordrecht, Kluwer, págs. 157-182.

Rapoport, T. R. (1993): "Verbs in Depictives and Resultatives", en Pustejovsky, J. (ed.) Semantics and the Lexicon, Dordrecht, Kluwer, págs. 163-184.

Real Academia Española (1973): Esbozo de una nueva gramática de la lengua española, Madrid, Espasa Calpe.

Rodríguez Espiñeira, M. J. (1991): "Los adjetivos incidentales como subtipo de los adjetivos predicativos", Verba, 18, págs. 255-274.

Sánchez López, C. (1999): "La negación", en Bosque, I. y V. Demonte (dirs.), págs. 2561-2634.

Suñer Gratacós, A. (1990): La predicación secundaria en español, tesis doctoral de la UAB.

Suñer Gratacós, A. (1999): "La aposición y otras relaciones de predicación en el sintagma nominal", en Bosque, I. y V. Demonte (dirs.), págs. 523-564.

Tornel Sala, J. L. (1996): Gramática y cognición: El predicativo, Alicante, Ed. Club Universitario.

Zagona, K. (1993): "Spanish adjectival secondary predicates, time adverbs and subevent structure", Cuadernos Lingüística, 1, págs. 317-354. 